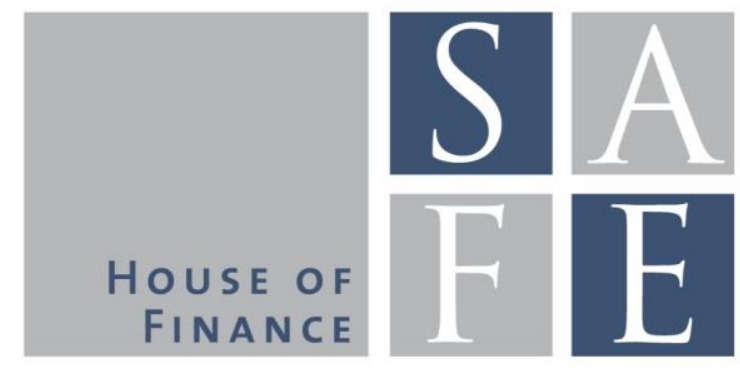

WORKING PAPER SERIES

Tobias Niedrig - Helmut Gründl

\title{
The Effects of Contingent Convertible (CoCo) Bonds on Insurers' Capital Requirements under Solvency II
}

SAFE Working Paper No. 98

SAFE I Sustainable Architecture for Finance in Europe A cooperation of the Center for Financial Studies and Goethe University Frankfurt 


\section{Non-Technical Summary}

In the aftermath of the financial crisis, the Liikanen Group recommended the issuance of contingent convertible ( $\mathrm{CoCo}$ ) bonds as a measure to reduce the moral hazard created by governments' safety nets as well as to enhance financial stability in the banking sector. This form of long-term debt with a fixed coupon rate automatically converts to equity when a bank approaches insolvency, i.e. when a predetermined trigger is met. Recently, CoCos can qualify as Additional Tier 1 or Tier 2 capital under Basel III depending on their structure and characteristic. The current Basel III proposal requires capital-qualifying debt to be loss-absorbing, i.e. debt that is written off or converted into common equity if the specified trigger is met. Consequently, the use of $\mathrm{CoCo}$ bonds as a funding instrument has become more widespread among banks during the past few years.

To maximize the stabilizing effect on the financial system, CoCo bonds should be held outside the banking industry. According to the Liikanen Group, life insurance companies seem to be optimal CoCo holders as they are diversified financial institutions with long-term maturities on their funding side and restrictive termination rights. In fact, life insurers are already the largest purchasers of bank bonds in Europe. Especially in the current low interest rate environment, which leads to a decline in the returns of fixed-income securities, life insurers might favor higher yielding fixed-income securities, such as CoCo bonds.

In this paper, we aim at assessing the effects of holding CoCo bonds on life insurers' risk-based capital requirements under the upcoming European Solvency II standards. Therefore, we develop a stylized model with a direct financial connection between banking and insurance and study the effects of various types of bonds such as non-convertible bonds, write-down bonds and CoCos on banks' and insurers' risk situations. To assess the effect of the conversion on insurers' capital requirements, besides using the Solvency II standard model, we develop an internal model that ex-ante anticipates possible future conversions, i.e. bank share holdings.

Our contribution provides an insight to understand the impacts of holding CoCo bonds implied by the Solvency II standards that are about to come into power by 2016. Policymakers responsible for determining whether particular contingent capital designs will qualify to meet Basel III capital requirements and ultimately add to the financial stability get a hint in how CoCo bonds are an attractive investment category for life insurers as an important investor group.

The numerical results reveal large differences in the capital charges for insurers under the standard model and the internal model. Since the current standardized assessment of market risk depends on relatively crude risk weights, it is not able to reflect the entire risk profile of a CoCo bond. In contrast, an internal model can recognize the full risk return profile through dynamic modeling techniques and therefore evaluates the actual risk situation of the company. Moreover, we find that the standard model can mislead CoCo investors and does produce economically irrational incentives.

From the internal model, we learn that capital requirements for CoCo bonds increase with increasing trigger value, decreasing conversion ratio as well as increasing bank risk. In addition, CoCos lead to higher capital charges than non-convertible bonds if bank risk is low, and to lower capital requirements if bank risk is high. For high bank risk, insurers clearly benefit from buying CoCos due to lower capital charges and a higher coupon rate. In this case, holding a CoCo clearly dominates holding a non-convertible bond. 
The results of our analysis depend on both the calibration of the model and on the necessary simplifications adopted. The insurer's capital requirements depend on its simplified asset structure and indirectly on the stylized liability structure of the bank. Furthermore, the analysis with respect to the upcoming Solvency II regulation implies the use of the Value-at-Risk measure. Under other regulatory frameworks such as the Swiss Solvency Test, insurance companies have to quantify capital requirements using the Tail Value-at-Risk. A change in the risk measure can change our results and thus the regulatory incentives for insurance companies to buy CoCos.

Our results have profound economic implications. The analyses reveal that the current set-up and calibration of the Solvency II standard formula for market risk are inadequate with respect to the treatment of contingent convertible bonds. By highlighting substantial weaknesses of the market risk module, we hope that our results provide an additional impulse for improving it. 


\title{
The Effects of Contingent Convertible (CoCo) Bonds on Insurers' Capital Requirements under Solvency II
}

\author{
Tobias Niedrig, Helmut Gründl ${ }^{\dagger}$ \\ This version: February 2015
}

\begin{abstract}
The Liikanen Group proposes contingent convertible ( $\mathrm{CoCo})$ bonds as a potential mechanism to enhance financial stability in the banking industry. Especially life insurance companies could serve as CoCo bond holders as they are already the largest purchasers of bank bonds in Europe. We develop a stylized model with a direct financial connection between banking and insurance and study the effects of various types of bonds such as non-convertible bonds, write-down bonds and CoCos on banks' and insurers' risk situations. In addition, we compare insurers' capital requirements under the proposed Solvency II standard model as well as under an internal model that ex-ante anticipates additional risks due to possible conversion of the CoCo bond into bank shares. In order to check the robustness of our findings, we consider different CoCo designs (write-down factor, trigger value, holding time of bank shares) and compare the resulting capital requirements with those for holding non-convertible bonds. We identify situations in which insurers benefit from buying $\mathrm{CoCo}$ bonds due to lower capital requirements and higher coupon rates. Furthermore, our results highlight how the Solvency II standard model can mislead insurers in their CoCo investment decision due to economically irrational incentives.
\end{abstract}

Keywords: Contingent Convertible Capital, CoCo Bond, Basel III, Solvency II, Life Insurance, Interconnectedness

JEL Classification: G11, G21, G22, G28, G32

\section{Introduction}

In its 2012 "Report of the European Commission's High-level Expert Group on Bank Structural Reform" , the Liikanen Group strongly recommends the issuance of contingent convertible

\footnotetext{
${ }^{*}$ Corresponding author. Address: Theodor-W.-Adorno-Platz 3, 60629 Frankfurt, Germany. Telephone: +4969798 33683. E-mail: niedrig@finance.uni-frankfurt.de.

${ }^{\dagger}$ The authors are with the International Center for Insurance Regulation at the Goethe University Frankfurt and the Research Center "Sustainable Architecture for Finance in Europe" (SAFE). We are grateful to Elia Berdin, Enrico Biffis, Nadine Gatzert and to the participants at the following conferences and seminars for advice and suggestions: SAFE-ICIR Workshop on Banking and Insurance 2014, 18th International Congress on Insurance: Mathematics and Economics, 47th Annual Meeting of the Southern Risk and Insurance Association and the Annual Congress of the German Insurance Science Association 2015. We gratefully acknowledge research support from the Research Center SAFE, funded by the State of Hessen initiative for research LOEWE.

${ }^{1}$ See Liikanen Group (2012).
} 
debt as a potential mechanism to reduce the moral hazard created by governments' safety nets as well as to enhance financial stability in the banking sector. This form of long term debt (also called contingent convertibles or CoCo bonds) with a fixed coupon rate automatically converts to equity when a bank approaches insolvency, i.e. when a predetermined trigger is met. ${ }^{2}$ Upon conversion, a bank immediately replenishes its equity capital base, while at the same time reducing its interest payment obligations. As a result, CoCo bonds have the potential to offer the advantages of debt in good times and equity in crisis times.

Over the past few years, the use of CoCos as a funding instrument has become more widespread among banks. ${ }^{3}$ Under Basel III, CoCos can qualify as Additional Tier 1 or Tier 2 capital depending on their structure and characteristic. The current Basel III proposal requires capital-qualifying debt to be loss-absorbing, i.e. debt that is written off or converted into common equity if the specified trigger is met. ${ }^{4}$

To maximize the stabilizing effect on the financial system, CoCo bond holders may not hedge themselves in the banking sector and should not experience refinancing difficulties when suffering losses on their investments. ${ }^{5}$ Diversified financial institutions with long term maturities on their funding side and restrictive termination rights, such as life insurance companies, seem to fit this profile in particular. In fact, life insurers are already the largest purchasers of bank bonds in Europe owning around $11 \%$ of European bank debt. ${ }^{6}$ Especially in the current low interest rate environment, which leads to a decline in the returns of fixed-income securities, life insurers might favor higher yielding fixed-income securities, such as CoCo bonds.

In our contribution, we aim at assessing the effects of holding CoCo bonds on life insurers' risk-based capital requirements under the upcoming European Solvency II standards. We will illustrate under which conditions Solvency II provides appropriate incentives for life insurers to hold CoCo bonds. As a benchmark, we use the treatment of non-convertible bank bonds. From a bank's point of view, non-convertible bonds cannot replenish its equity capital in case of high losses. In contrast, a CoCo issuance can contribute to a reduction in the bank's default risk due to an immediate improvement in the bank's equity capital after a larger bank loss. In addition, interest payments on CoCos are tax deductible. From the insurer's point of view, after the bank realizes a loss, capital requirements for non-convertible bonds could increase due to the apparent

\footnotetext{
${ }^{2}$ The trigger is typically a fixed core capital ratio set by the regulator. See for example FINMA (2011).

${ }^{3}$ See Avdjiev et al. (2013, pp. 48-49). Banks that have issued CoCo bonds include Lloyds Bank (2009), UBS (2012), Barclays (2013) and Deutsche Bank (2014).

${ }^{4}$ See BIS (2011).

${ }^{5}$ See Krahnen (2013, p. 15).

${ }^{6}$ See Insurance Europe and Oliver Wyman (2013).
} 
prospect of future write-downs. However in the case of CoCos, insurers capital requirements might decrease due to the lower default risk of the bank. Thus, CoCo bonds can contribute to stabilize the financial system at large.

In our model, we study a variety of CoCo designs and allow for partial conversion which has important implications for investors: as CoCos convert to equity, bond holders become shareholders and thus share any costs or benefits to shareholders of subsequent conversions. ${ }^{7}$ To assess the effect of the conversion on insurers' capital requirements, besides using the Solvency II standard model, we develop an internal model that ex-ante anticipates possible future bank share holdings. From the resulting capital requirements for insurers, we study the sensitivity with respect to the CoCo bond design (trigger value, conversion ratio, holding time of bank shares) and the bank's risk appetite.

Our contribution provides an insight to understand the impacts of holding CoCo bonds implied by the Solvency II standards that are about to come into power by 2016. Policymakers responsible for determining whether particular contingent capital designs will qualify to meet Basel III capital requirements and ultimately add to the financial stability get a hint in how CoCo bonds are an attractive investment category for life insurers as an important investor group.

The remainder of the paper is organized as follows. Section 2 reviews the relevant literature on financial regulation and contingent convertible capital. Section 3 introduces our model framework specifying the characteristics of banks and insurers as well as their financial connection. In section 4 we describe the data and the calibration we adopt. Section 5 shows the implications for banks' risk situations and insurers' solvency capital requirements using the Solvency II standard model as well as an internal model. Subsequently, we present our findings on the sensitivity of the capital requirements and discuss our results. Section 6 concludes.

\section{Literature Review}

Two strands of literature are vital for our study: literature on financial regulation and literature on contingent convertible capital. Academic work on bank and insurance regulation is extensive and mainly concentrates on qualitative analyses and comparisons of potential regulatory effects. The Bank for International Settlements (2011) gives an overview of the Basel Accords, the framework and implementing measures. In the context of Solvency II, Eling et al.

\footnotetext{
${ }^{7}$ See Glasserman and Nouri (2012).
} 
(2007) describe the development and main characteristics.

A qualitative study comparing the capital standards of Basel II/III and Solvency II is done by Gatzert and Wesker (2012). Among other things, the authors conclude that due to the complexity of both regulatory systems, further research is needed to analyze adverse interaction effects between the two regulatory systems.

The amount of literature on contingent capital is growing rapidly. Originally proposed by Flannery (2005), the key features of contingent capital, pricing and valuation techniques, and its application in the insurance industry have been carefully outlined in Shang (2013). Alternative proposals for the design of contingent capital have led to further work on valuation. Pennacchi (2011) compares different CoCo designs by simulation in a jump-diffusion model of a bank's assets and shows how conversion decreases shareholder returns in high risk banks.

Glasserman and Nouri (2012) analyze the case of contingent capital with a capital-ratio trigger and partial and on-going conversion. The capital ratio is based on accounting or book values to approximate the regulatory ratios that determine capital requirements for banks.

To our knowledge, our paper is the first to extend the analysis of contingent convertible capital towards the effects of a CoCo bond investment on the risk situation of insurance companies under the upcoming Solvency II standards.

\section{Model Framework}

We develop a stylized model of a bank and a life insurance company. The bank provides loans that are financed by equity capital, deposits and additional bank debt (non-convertible debt or contingent convertible debt). The life insurer features an existing stock of savings contracts including minimum guaranteed returns. Figure 1 gives an outline of how the bank and the life insurer are connected.

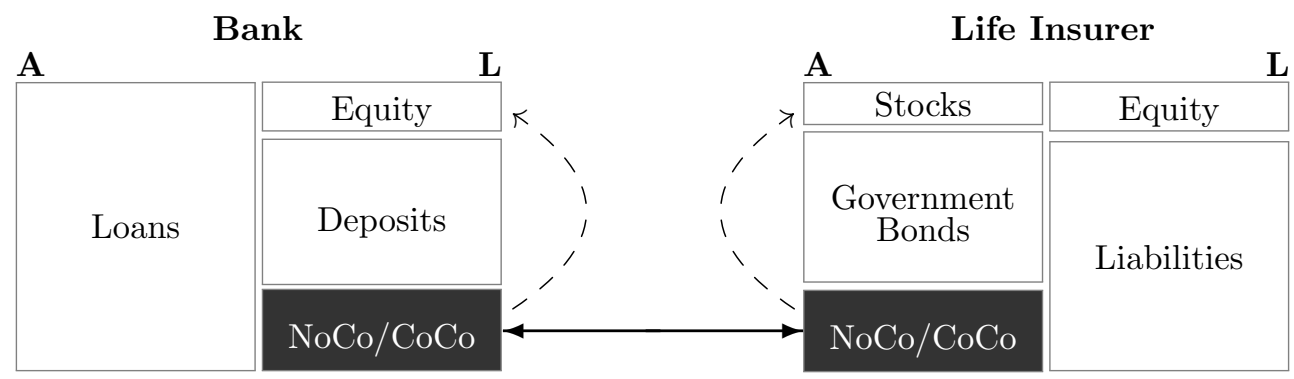

Figure 1: Financial connection between bank and insurance company. 
The life insurer's asset side consists of three asset classes: stocks, non-convertible (NoCo) or CoCo bonds and sovereign bonds. The financial connection between bank and life insurer stems from the insurer's investment into the NoCo or CoCo bond.

The model starts at time $t=0$, when both institutions are endowed with equity capital according to the regulatory requirements. In addition, the bank issues a bond (either contingent convertible or non-convertible), which the life insurer buys as part of its investment strategy. To comply with the regulatory minimum one-year survival probability under the upcoming European insurance regulation, we gauge the insurer's assets and liabilities at $t=1$. Thus, if the bank issues a CoCo bond, we evaluate the bank's equity capital ratio quarterly. ${ }^{8}$ In case the bank's quarterly equity capital ratio violates the regulatory minimum level, a (partial) conversion of the CoCo bond is triggered. As a result, the insurer's capital requirements could change due to the conversion of the CoCo bond into bank shares.

Our model entails several idealizations and simplifications. We assume that equity capital ratios can be observed quarterly to evaluate if a conversion is needed. The bank's asset volatility is the driver of both the likelihood of conversion of debt to equity as well as the upside potential of equity following conversion.

\subsection{The Bank}

At time $t=0$, the bank holds a portfolio of loans with initial value $V_{0}$. We assume the return on the loan portfolio to be normally distributed with mean $\mu_{V}$ and standard deviation $\sigma_{V}$, that is $r_{V} \sim \mathcal{N}\left(\mu_{V}, \sigma_{V}^{2}\right)$. The bank's capital structure is comprised of equity capital $\left(E_{t}^{B}\right)$, deposits $\left(D_{t}\right)$ and a bond denoted $B_{t}$. Deposits are the most senior claim, the interest rate on deposits is assumed to equal the one-year risk-free rate $\left(r_{D}=r_{f_{1}}\right)$. At time $t=0$, equity capital fulfills the regulatory capital ratio $\left(k=E^{B} / V\right)$ such that $E_{0}^{B} \geq V_{0} \cdot k$. The bank's equity capital satisfies

$$
E_{t}^{B}=\left(V_{t}-\left(B_{t}+D_{t}\right)\right)^{+},
$$

where $(\cdot)^{+}$stands for $\max \{\cdot ; 0\}$.

\footnotetext{
${ }^{8}$ A bank's risk-weighted assets are usually determined at the end of each quarter. See Zähres (2011, p. 7).
} 


\subsubsection{Debt}

At time $t=0$, the bank issues either a non-convertible bond $(B B)$ or a contingent convertible bond $(C C)$. Both are subordinated to deposits. For simplicity reasons, we assume that the face value $\left(B^{F V}\right)$ as well as the maturity $\left(T_{B}\right)$ of either bond is the same at $t=0\left(B_{B B}^{F V}=B_{C C}^{F V}=B^{F V}\right.$ and $\left.T_{B B}=T_{C C}=T_{B}\right)$. For issued bonds, the bank has to pay the coupon $B_{B B}^{C}$ or $B_{C C}^{C}$. The only difference between both bond types is the presence of a trigger value for the contingent convertible bond which is assumed to equal the regulatory equity capital ratio $k$. Conversion thus occurs when the bank's equity capital ratio falls below $k .^{9}$

To determine the respective cash flow of the CoCo, we forecast the development of the bank's assets until the maturity of the bond. Until conversion, the investor collects yearly interest payments. Upon conversion, the CoCo's face value will be (partly) converted into bank shares. If the bank's financial situation deteriorates during the term of the CoCo, the investor will thereupon receive either reduced interest payments (partly conversion) or no interest payments (full conversion) plus the value of the bank shares. We thus have to incorporate future share price movements in the model. Finally, we discount the resulting payouts.

We evaluate the bank's equity capital ratio on a quarterly basis, that is $t \in\left\{0.25,0.5, \ldots, T_{B}\right\}$. The fair coupon $c^{*}$, that compensates bond investors for additional risks, is the unique coupon so that the face value equals the present value at time $t=0 .{ }^{10} c^{*}$ is then the fair coupon rate at the bonds' issue date. ${ }^{11}$ We denote the nominal coupon for the non-convertible bond as $B_{B B}^{C}=c_{B B}^{*} \cdot B^{F V}$ and as $B_{C C}^{C}=c_{C C}^{*} \cdot B^{F V}$ for the CoCo. For the valuation of either bond type at time $t=0$, the insurer calculates the market values of the bond. For the valuation of the CoCo bond at time $t=0$, we introduce the following stopping times: ${ }^{12}$

$$
T^{(0)}=0, \quad T^{(1)}=\min \left\{t \in\left\{0.25,0.5, \ldots, T_{B}-0.25, T_{B}\right\} \mid E_{t}^{B}<k \cdot V_{t}\right\}
$$

and

$$
\begin{gathered}
T^{(j)}=\min \left\{t>T^{(j-1)}, t \in\left\{0.25,0.5, \ldots, T_{B}-0.25, T_{B}\right\} \mid E_{t}^{B}<k \cdot V_{t}\right\}, \\
\text { for } j=2, \ldots, 4 \cdot T_{B} .
\end{gathered}
$$

$T^{(j)}$ can be interpreted as the point in time when the bank's equity falls below the trigger value

\footnotetext{
${ }^{9}$ Note that for simplicity reasons, we assume that the bank's assets exhibit a risk weight of $100 \%$. Thus, total assets $V_{t}$ equal the amount of risk-weighted assets at time $t$.

${ }^{10}$ We find $c^{*}$ by valuing the bonds discounted expected cash flows for a given bank risk and then iterating over $c$ until we find the coupon value $c^{*}$ such that the face value equals the present value. See Pennacchi (2011).

${ }^{11}$ See Glasserman and Nouri (2012, p. 1819).

${ }^{12}$ See Brigo et al. (2013, p. 12) for a similar approach.
} 
for the $j$-th time. To account for the bond's size, $\delta_{t}$ represents the number of trigger events $\left(T^{(j)}\right)$ until time $t$ for which the total amount of capital that is converted till $T^{\left(\delta_{t}-1\right)}$ does not exceed the bond's face value $B^{F V}$. It follows

$$
\delta_{t}=\max \left\{j \in\left\{0,1, \ldots, 4 \cdot T_{B}\right\} \mid T^{(j)} \leq t \text { and } \sum_{i=1}^{j-1}\left(k \cdot V_{T^{(i)}}-E_{T^{(i)}}^{B}\right)<B^{F V}\right\}
$$

for $t \in\left[0, T_{B}\right]$.

Since every (partial) conversion reduces the CoCo bond's face value by the amount of converted capital for the following payoffs (for the $j$-th conversion that is $k \cdot V_{T^{(j)}}-E_{T^{(j)}}$ ), the bond's payoff at time $t$ is given by

$$
C F_{t}^{C C}=c_{C C}^{*} \cdot\left(B^{F V}-\sum_{j=1}^{\delta_{t}}\left(k \cdot V_{T^{(j)}}-E_{T^{(j)}}^{B}\right)\right)^{+}, \quad \text { for } t=1,2, \ldots, T_{B}-1
$$

where $c_{C C}^{*}$ represents the coupon rate, $B^{F V}$ the initial face value and $\sum_{j=1}^{\delta_{t}}\left(k \cdot V_{T^{(j)}}-E_{T^{(j)}}^{B}\right)$ the converted amount up to time $t$. Consequently, the investor's payoff at maturity (face value plus interest payment) is given by

$$
C F_{T_{B}}^{C C}=\left(1+c_{C C}^{*}\right) \cdot\left(B^{F V}-\sum_{j=1}^{\delta_{T_{B}}}\left(k \cdot V_{T^{(j)}}-E_{T^{(j)}}^{B}\right)\right)^{+}
$$

To obtain the value of the expected stock holdings, we first notice that

$$
\Delta_{1}=\frac{\phi\left(k \cdot V_{T^{(1)}}-\left(E_{T^{(1)}}^{B}\right)^{+}\right)}{k \cdot V_{T^{(1)}}}
$$

is the fraction of the bank's equity capital that the investor holds directly after the first conversion in $T^{(1)}$, where $\phi \in[0,1]$ is the conversion ratio of the CoCo bond and $k \cdot V_{T^{(1)}}$ the bank's replenished equity capital after the first conversion. If there is a second conversion, the fraction of the bank's equity that the investor holds is

$$
\Delta_{2}=\frac{E_{T^{(2)}}^{B} \Delta_{1}+\phi\left(k \cdot V_{T^{(2)}}-\left(E_{T^{(2)}}^{B}\right)^{+}\right)}{k \cdot V_{T^{(2)}}}
$$

where $E_{T^{(2)}}^{B} \Delta_{1}$ represents the absolute value of the bond investor's fraction of the bank's equity capital prior to the second conversion. Iterating this calculation, after $\delta_{T_{B}}$ conversions the 
fraction of the bank's equity capital that the bond investor holds is

$$
\Delta_{\delta_{T_{B}}}=\sum_{j=1}^{\delta_{T_{B}}} \frac{\phi\left(k \cdot V_{T^{(j)}}-\left(E_{T^{(j)}}^{B}\right)^{+}\right)}{k \cdot V_{T^{(j)}}} \prod_{i=j+1}^{\delta_{T_{B}}} \frac{E_{T^{(i)}}^{B}}{k \cdot V_{T^{(i)}}} .
$$

By convention, empty products are equal to 1 , that is $\prod_{i=j}^{n} f(i)=1$ for all $n<j$ and all functions $f$. If the remaining face value after the $\left(\delta_{T_{B}}-1\right)$-th conversion is less than the required capital in the $\delta_{T_{B}}$-th conversion, the investor receives only the additional fraction of equity that is equivalent to the remaining face value, so that its overall fraction of equity equals

$\Delta_{\delta_{T_{B}}}^{*}:=\frac{\left.E_{T^{\left(\delta_{T_{B}}\right)}}^{B} \Delta_{\delta_{T_{B}}-1}+\phi \min \left\{B^{F V}-\sum_{j=1}^{\delta_{T_{B}}-1}\left(k \cdot V_{T^{(j)}}-E_{T^{(j)}}^{B}\right), k \cdot V_{T^{\left(\delta_{T_{B}}\right.}}\right)-\left(E_{T^{\left(\delta_{T_{B}}\right)}}^{B}\right)^{+}\right\}}{\left.k \cdot V_{T^{\left(\delta_{T_{B}}\right.}}\right)}$.

Since the market value of the CoCo bond at time $t=0$ is equal to the expectation of the sum of the discounted bond payoff and discounted stock holdings under a risk-neutral measure $\mathbb{Q}$, it can be computed as follows:

$$
M V_{0}\left(C C_{0}\right)=\mathbb{E}^{\mathbb{Q}}[\underbrace{\sum_{t=1}^{T_{B}} C F_{t}^{C C} \cdot e^{-t \cdot r_{f_{t}}}}_{\text {discounted bond payoff }}+\underbrace{E_{T_{B}}^{B} \cdot \Delta_{\delta_{T_{B}}}^{*} \cdot e^{-T_{B} \cdot r_{f_{T_{B}}}}}_{\text {discounted value of bank shares }}] .
$$

As a result, the market value of the CoCo bond directly depends on the risk situation of the bank. Note that we can also use Equation (11) to calculate the market value of a non-convertible bond. In this case, the cash flow equals $c_{B B}^{*} \cdot B^{(F V)}$ as long as the bank is solvent. If the bank defaults at time $T^{(1)}<T_{B}$, the payout is zero afterwards. Hence, we set the trigger value in the first part of Equation (11) to zero $(k=0)$. Since there is no conversion, we set the second part of Equation (11) to zero $(\phi=0)$.

Note that if we set the second part of Equation (11) to zero and keep $k>0$, the resulting market value would correspond to a so called write-down bond. Write-down bonds are financing instruments that are written down rather than being converted to equity.

Finally, to calculate the market value of a CoCo bond for which investors would sell the shares received at conversion immediately, we replace $\Delta_{\delta_{T_{B}}}^{*}$ with

$$
\Delta_{S A C}=\frac{\sum_{j=1}^{\delta_{T_{B}}} \phi\left(k \cdot V_{T^{(j)}}-\left(E_{T^{(j)}}^{B}\right)^{+}\right)}{E_{T_{B}}^{B}} .
$$

We can thus distinguish between the three following convertible bond types besides the 
non-convertible bond:

(i) Write-down bond: Upon conversion, the face value is written down (bail-in). Bond holders do not receive bank shares. The release of the liabilities generates exceptional gains that the bank can allocate to retained earnings.

(ii) Contingent convertible bond, sold at conversion (SAC): Upon conversion, the face value is (partially) converted to equity. Bond holders receive bank shares in relation to the bonds' converted face value. After receiving the bank shares, the investor immediately sells them.

(iii) Contingent convertible bond, held to maturity (HTM): same as (ii) with the exception that bank shares will be held to the maturity of the bond.

\subsection{The Life Insurer}

We model a stylized life insurance company with an outstanding stock of endowment savings contracts. Duration and predictability of the liabilities, which typically consist of a portfolio of generation overlapping contracts, usually determine a life insurer's investment strategy. These liabilities tend to have long maturities, which settles the need for stable sources of income. Therefore, the allocation of assets is vastly dominated by government and corporate bonds, among these in particular bank bonds. ${ }^{13}$ In this model, we focus on three asset classes: stocks $(S T)$, bank bonds $(B)$ - either NoCo or CoCo - and sovereign bonds $(G B)$.

The book value of the insurer's liabilities at $t=0$ is denoted by $L_{0}$. Also at time $t=0$, the insurer's shareholders endow the company with equity capital $E_{0}^{I}$ according to Solvency II. Neither mortality nor surrender risk are mapped, thus only financial risk is taken into consideration.

For the insurer's stock holdings, we assume a normally distributed rate of return $r_{S T}$ with mean $\mu_{S T}$ and standard deviation $\sigma_{S T}$, that is $r_{S T} \sim \mathcal{N}\left(\mu_{S T}, \sigma_{S T}^{2}\right)$. In addition, the insurer earns interest rates on bank bonds (either $r_{B B}$ or $r_{C C}$ depending on the bond type, see section 3.1.1). For government bonds, we assume a rate of return to equal to the risk free rate: $r_{G B}=r_{f_{T_{G B}}}$ with $T_{G B}$ representing the maturity of government bonds.

The liability portfolio at time $t=0$ includes an initial stock of contracts with minimum guaranteed returns. We denote the overall minimum guaranteed rate of return of the portfolio as $r_{G}$. In addition, we assume a time to maturity of $T_{L}$ years. For regulatory purposes, i.e. to determine the value of the liabilities in the solvency balance sheet, we approximate the market

\footnotetext{
${ }^{13}$ See GDV (2014, p.28).
} 
consistent value $(M C V)$ of liabilities at time $t=0$ as follows

$$
M C V_{0}\left(L_{0}\right)=\frac{L_{0} \cdot\left(1+r_{G}\right)^{T_{L}}}{e^{r_{f_{L}} \cdot T_{L}}},
$$

where $r_{f_{T_{L}}}$ is the $T_{L}$-year risk-free interest rate. The numerator reflects the year-by-year accrual of the guarantees as it is a common product feature for endowment savings contracts. For the sake of simplicity, no profit participation of policyholders is taken into account.

\subsection{Insurer's Capital Requirements using the Solvency II Standard Model}

Solvency II aims to reflect the full range of risks faced by insurers to achieve a one-year company solvency probability of at least $99.5 \% .{ }^{14}$ Similar to the Basel Accords, it is made up of three pillars, providing quantitative capital requirements in Pillar I, qualitative corporate governance and risk management regulations in Pillar II, as well as disclosure and transparency rules in Pillar III.

Pillar I is structured according to different risk (sub)modules that are calibrated in accordance with a $0.5 \%$ Value-at-Risk (VaR) of the "basic own funds $(B O F)$ ", the difference between the market value of assets and liabilities over a period of one year. Changes in the BOF as a result of pre-defined shocks scenarios are denoted by $\triangle B O F$. Hence, a negative $\triangle B O F$ implies the need for additional equity capital. The resulting Solvency Capital Requirements $(S C R \mathrm{~s})$ are aggregated taking into account predefined correlations. Under the standard model, we will focus on the capital requirements resulting from the market risk module. ${ }^{15}$

\subsubsection{Market Risk}

Market risk is defined as the volatility of market rates and prices of financial assets. The module comprises interest rate risk, equity risk, property risk, spread risk, currency risk, concentration risk and counter-cyclical premium risk. We exclude concentration risk as well as counter-cyclical premium risk from the analyses. Following Laas and Siegel (2013), we further assume that the insurance company does not invest into property and is able to perfectly hedge exchange rate risk at negligible transaction costs.

\footnotetext{
${ }^{14}$ See EIOPA (2013b, p. 116).

${ }^{15}$ Among European life insurers, market risk accounts for up to $70 \%$ of the overall $S C R$. See Fitch Ratings (2011).
} 
The market risk sub-modules are aggregated to an overall $S C R$ for market risk as follows

$$
S C R_{m k t}=\sqrt{\sum_{r \times c}{\operatorname{Corr} M k t_{r, c} \cdot M k t_{r} \cdot M k t_{c}}_{,}}
$$

with $r, c \in[i n t, e q u, s p r]$ representing the capital requirements for interest rate risk, equity risk and spread risk, and $\operatorname{Corr} M k t_{r, c}$ the correlation coefficients according to the given correlation matrix. ${ }^{16}$

\subsubsection{Interest Rate Risk}

Interest rate risk involves all changes to the market values of assets and liabilities due to movements in the term structure of interest rates over a one-year horizon. The capital requirement for interest rate risk $\left(M k t_{i n t}\right)$ includes predefined scenarios where the interest rates are subject to an upward $\left(s^{u p}(t)\right)$ and a downward $\left(s^{\text {down }}(t)\right)$ shock, with $t$ representing the time to maturity.

The framework assumes that the interest rate shock manifests itself as an immediate change to the interest rates. It follows

$$
r_{f_{t}}^{j}=s^{j}(t) \cdot r_{f_{t}}
$$

with $j \in[u p$, down $]$ and $r_{f_{t}}^{j}$ representing the shocked interest rate for maturity $t$. The shocks are predefined and given by EIOPA (2013b, pp. 136-137). The capital requirement for interest rate risk after shock $j$ is determined as the change in the net value of asset and liabilities $\left(M k t_{i n t}^{j}\right)$ due to the re-valuation of all interest rate sensitive exposures using altered term structures. To determine the capital requirement we recalculate the market value of all fixed income securities at time $t=0$ under the shocked term structures using Equation (11). The altered market consistent value of liabilities is calculated using Equation (13). The capital requirements for interest rate risk are thus given by

$$
M k t_{\text {int }}=\left(\Delta B O F_{\text {int }}^{\text {up }} ; \Delta B O F_{\text {int }}^{\text {down }}\right)^{+}
$$

With respect to our model framework, the expected capital requirements for interest rate risk at time $t=0$ might differ with the bond type. This is due to the different payout profiles of the non-convertible and contingent convertible bond types.

\footnotetext{
${ }^{16}$ See EIOPA (2013b, p. 133).
} 


\subsubsection{Equity Risk}

The measurement of equity risk is carried out in two steps. First, all assets that are sensitive to the volatility of equity prices are divided into two categories: "Type 1 equities" and "Type 2 equities". The category "Type 1" comprises all equities that are listed on organized capital markets in the EEA or OECD countries. The second class includes private equity, commodities, hedge funds, alternative investments, non-listed equities and exposures in emerging markets. ${ }^{17}$

In our model, we consider only equities of the "Type 1" category. These equities are subjected to a pre-specified shock $s^{e q u}=39 \%$. It follows

$$
M k t_{e q u}=\Delta S T=s^{e q u} \cdot S T
$$

The standard model is thus not able to anticipate possible stock holdings over the time horizon of one year.

To account for the possibility of a conversion in the equity risk sub-module if the insurer holds a CoCo bond, we include the expected discounted stock holdings up to time $t=1$ due to possible conversions $\left(S T_{0}^{C C}\right)$. It follows

$$
S T_{0}^{C C}=\mathbb{E}^{\mathbb{Q}}\left[E_{1}^{B} \cdot \Delta_{\delta_{1}} \cdot e^{-r_{f_{1}}}\right] \cdot{ }^{18}
$$

Thus, the expected capital requirement for equity risk at time $t=0$ is

$$
M k t_{e q u}^{C C}=s^{e q u} \cdot\left(S T_{0}+S T_{0}^{C C}\right)
$$

in case of the CoCo and

$$
M k t_{e q u}^{B B}=s^{e q u} \cdot S T_{0}
$$

in case of the non-convertible bond. ${ }^{19}$

\subsubsection{Spread Risk}

Spread risk can be defined as the variability of an asset's value due to changes in the credit spreads. This risk category comprises specifically corporate bonds, subordinated debt securities, and hybrid debt. The spread risk sub-module contains three sub-groups: spread risk on bonds and loans other than residential mortgage loans, spread risk on repackaged loan products and

\footnotetext{
${ }^{17}$ See EIOPA (2013b, p. 139).

${ }^{18} S T_{0}^{C C}$ amounts to the second part of Equation (11) evaluated at time $t=1$.

19 The second case also applies to a write-down bond.
} 
spread risk on credit derivatives. ${ }^{20}$ The latter encompasses credit default swaps, total return swaps and credit linked notes. The second sub-module includes repackaged loan products i.e. structured credit products. Since CoCo bonds fit neither of these two categories, we consider them to be part of the first group.

Under the standard approach, the capital requirement for corporate bonds $\left(M k t_{s p r}^{b o n d}\right)$ that are exposed to spread risk is determined as the result of a pre-defined scenario

$$
M k t_{\text {spr }}^{\text {bond }}=(\triangle B O F \mid \text { spread shock on bond })^{+} .
$$

Thus, the spread risk on a bond is the immediate effect on the net value of asset and liabilities expected in the event of an instantaneous decrease of the market value of the bond due to the widening of the credit spread. The quantification is as follows

$$
M k t_{s p r}^{\text {bond }}=M V_{0}\left(B_{0}\right) \cdot M D_{0}\left(B_{0}\right) \cdot F^{u p}(\text { rating }),
$$

with $M V_{0}\left(B_{0}\right)$ representing the value of the credit risk exposure at $t=0, M D_{0}\left(B_{0}\right)$ the modified duration of the bond at $t=0$ and $F^{u p}$ (rating) being a function of the rating class of the bond issuer which is calibrated to deliver a shock consistent with a $99.5 \% \mathrm{VaR}^{21}$ The risk factor contains six credit quality steps (see EIOPA (2013c, p. 45)). To determine $F^{u p}$ (rating), we first calculate the bank's probability of default at time $t=0\left(\pi_{0}^{B}\right)$ and assign a rating to the resulting value according to Reichling et al. (2007, p. 104), and then use the predefined values by EIOPA (2013b, pp. 148-149).

As a result, the required capital for spread risk in our model is

$$
M k t_{s p r}^{C C}=M V_{0}\left(C C_{0}\right) \cdot M D_{0}\left(C C_{0}\right) \cdot F^{u p}\left(\pi_{0}^{B, C C}\right)
$$

in case of the CoCo bond and

$$
M k t_{s p r}^{B B}=M V_{0}\left(B B_{0}\right) \cdot M D_{0}\left(B B_{0}\right) \cdot F^{u p}\left(\pi_{0}^{B, B B}\right)
$$

in case of a non-convertible bond, with $\pi_{0}^{B, C C}$ representing the bank's probability of default given a CoCo issuance and $\pi_{0}^{B, B B}$ the bank's default probability given the issuance of a nonconvertible bank bond. At time $t=0$, the value of the credit risk exposure is the same for

\footnotetext{
${ }^{20}$ See EIOPA (2013b, pp. 147-154).

${ }^{21}$ See EIOPA (2013b, p. 148).
} 
both bond types, independent of the bank's riskiness $\left(M V_{0}\left(C C_{0}\right)=M V_{0}\left(B B_{0}\right)=M V_{0}\left(B_{0}\right)\right)$. However, the modified duration and the risk factor might differ. In addition, the CoCo issuing bank might exhibit a smaller default probability and hence a smaller risk factor. This would for example imply that $F^{u p}\left(\pi_{0}^{B, C C}\right) \leq F^{u p}\left(\pi_{0}^{B, B B}\right)$ since $\pi_{0}^{B, C C} \leq \pi_{0}^{B, B B}$.

\subsection{Insurer's Capital Requirements using an Internal Model}

Under Solvency II, the regulator requires the insurance company's one-year default probability $\pi^{I}$ to be bound from above with $\pi^{I} \leq 0.5 \%$. To assess capital requirements, we develop an internal model. To calculate the $S C R$, we proceed in two steps:

(i) Project the insurer's assets and liabilities over a one-year horizon in order to evaluate the net asset value at time $t=1$.

(ii) Discount the value of the $99.5 \%$ quantile to $t=0$ to quantify the amount of equity capital which invested at $t=0$ will enable the insurer to avoid bankruptcy in $99.5 \%$ of cases.

Insolvency of the insurer occurs if the insurer's asset values are lower than the market consistent value of liabilities at time $t=1$, that is

$$
S T_{1}+M V_{1}\left(G B_{1}\right)+M V_{1}\left(B_{1}\right)<M C V_{1}\left(L_{1}\right),
$$

where $M V_{1}\left(B_{1}\right)$ is the market value of either the non-convertible bond $B B_{1}$ or the CoCo bond $C C_{1}$ at time $t=1$, dependent on what bond type the bank issued at $t=0$. For the valuation of either bond type at time $t=1$, the insurer determines the (remaining) market value of the bond using Equation (11).

To forecast the market value of the CoCo bond, the insurer takes into account the bank's development over a one-year horizon. Since a conversion at time $T^{(j)}<1$ leads to higher stock holdings between $T^{(j)}$ and $t=1$, that are subject to a higher volatility than bonds, insurers' capital requirements might increase.

For the book value of the insurer's liabilities at time $t=1$ follows

$$
L_{1}=L_{0} \cdot\left(1+r_{G}\right)
$$

For the market consistent value of liabilities at time $t=1$ follows

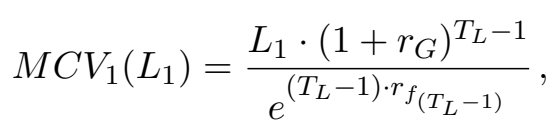


where $\left(T_{L}-1\right)$ is the remaining maturity of all insurance contracts and $r_{f_{T_{L}-1}}$ is the $\left(T_{L}-1\right)$-year risk-free interest rate at time $t=1$. Similar to the standard model, we use parallel shifts in the term structure of risk-free interest rates to account for possible interest rate changes.

Based on the forecasts of assets and liabilities, a distribution for the stochastic market value of the insurer's equity capital at time $t=1$ can be derived from

$$
E_{1}^{I}=S T_{1}+M V_{1}\left(G B_{1}\right)+M V_{1}\left(B_{1}\right)-M C V_{1}\left(L_{1}\right)
$$

We compute the $S C R$ at time $t=0$ as the discounted $99.5 \%$-VaR of the distribution of $E_{1}^{I}$. It follows

$$
S C R_{0}=e^{-\varphi}\left(-q^{E_{1}^{I}}(0.005)\right)^{+}
$$

with $\varphi$ representing the one-period discount rate ${ }^{22}$ and $q^{E_{1}^{I}}(\varepsilon)$ the value of the $\varepsilon$-quantile of the distribution of $E_{1}^{I} \cdot{ }^{23}$

Notwithstanding its parsimony, the internal model captures interest rate risk, equity risk and credit risk. In addition, the internal model captures possible conversions between $t=0$ and $t=1$ and quantifies capital charges accordingly.

\section{Calibration}

In Table 1, we report the parameters used in the numerical analysis. For the term structure of risk-free interest rates, we use data from the German Federal Bank as of December 2013. ${ }^{24}$

The parameters for the bank's loan portfolio are based on the return index of a corporate bond portfolio (Bank of America Merrill Lynch EMU Corporate Bond Index) from January 1973 until December 2013 (end of month). ${ }^{25}$ The bank's initial capital ratio is based on Deutsche Bank's common equity Tier 1 capital ratio as reported in the 2012 annual report. Similar to Pennacchi (2011, p. 19), we assume a five-year maturity for the newly issued non-convertible and contingent convertible bond. The stock market calibration is based on the German stock index (DAX) using the historical data from 1973 to 2013. We correlate the two stochastic processes (bank loans and stocks) based on empirical data over the same time period.

The insurer's initial stock investment proportion is set to $10 \% .{ }^{26}$ Furthermore, we set the

\footnotetext{
${ }^{22}$ We use the insurer's average asset return between time $t=0$ and $t=1$.

${ }^{23}$ See EIOPA (2013b, p. 116).

${ }^{24}$ Specifically, we use the following time series: WZ9810, WZ9812, WZ9814, WZ9816, WZ9818, WZ9820, WZ9822, WZ9824, WZ9826, WZ3431 and WZ3433. See (www.bundesbank.de).

${ }^{25}$ Source: Datastream.

${ }^{26}$ Based on the 2012 average stock and real estate investment weight of the largest life insurance enterprises in Europe. See EIOPA (2013a).
} 
insurer's initial bank bond portfolio weight to $5 \%$ of the total assets. The liabilities' time to maturity is based on the results of the second Quantitative Impact Study (QIS2). The growth rate of liabilities amounts to the current value of the maximum guaranteed interest rate set by the German Federal Financial Supervisory Authority. ${ }^{27}$

\begin{tabular}{lcc}
\hline \hline Parameter & Notation & Value \\
\hline Bank & & \\
Annual asset drift & $\mu_{V}$ & 0.05 \\
Initial equity capital ratio & $E_{0}^{B} / V_{0}$ & 0.125 \\
Bank/CoCo bond time to maturity & $T_{B}$ & 5 \\
Insurer & & \\
Annual stock market drift & $\mu_{S T}$ & 0.06 \\
Annual stock market volatility & $\sigma_{S T}$ & 0.25 \\
Initial stocks portfolio weight & $w_{S T}$ & 0.10 \\
Initial bank bond portfolio weight & $w_{B}$ & 0.05 \\
Government bond time to maturity & $T_{G B}$ & 10 \\
Liabilities time to maturity & $T_{L}$ & 12 \\
Liabilities growth rate & $r_{G}$ & 0.0175 \\
\hline \hline
\end{tabular}

Table 1: Parameters applied in the numerical analysis.

As for the bank, in the baseline calibration, we set the bond size to $5 \%$ of risk-weighted assets which roughly amounts to Deutsche Bank's Additional Tier 1 hybrid debt instruments in 2012.28 In addition, we set the trigger value to $k=5.125 \%$ which under Basel III, is the minimum trigger level required for a CoCo bond to qualify as Additional Tier 1 capital. ${ }^{29}$ Finally we follow Chen et al. (2013) and assume the conversion ratio to be $\phi=0.80$ meaning that there is a friction in the conversion of debt to equity. ${ }^{30}$ To assess the sensitivity of our results, we vary the trigger value (calibration II and III), the conversion ratio (calibration IV) $)^{31}$ as well as the bank risk. Table 2 presents the four different calibrations.

\begin{tabular}{ccc}
\hline \hline Calibration & Trigger $(k)$ & Conversion Ratio $(\phi)$ \\
\hline I (Baseline) & $5.125 \%$ & 0.80 \\
II & $6.125 \%$ & 0.80 \\
III & $4.125 \%$ & 0.80 \\
IV & $5.125 \%$ & 0.25 \\
\hline \hline
\end{tabular}

Table 2: Model calibrations.

\footnotetext{
${ }^{27}$ See BaFin (2012).

${ }^{28}$ See Deutsche Bank Annual Report 2012.

${ }^{29}$ See Avdjiev et al. (2013).

${ }^{30}$ See Chen et al. (2013, p. 22).

${ }^{31}$ The low conversion ratio $(\phi=0.25)$ in calibration IV corresponds to the issued CoCo bond by Rabobank in 2011 with a write-down factor of $75 \%$. See Corcuera et al. (2013, p. 134).
} 
For the underlying simulation of the bank loans and stock market and thus the bank's and insurer's balance sheets, we simulate 100,000 iterations. To assess the insurer's solvency situation at $t=0$ and $t=1$, we simulate 100,000 1-year developments of the bank as well as the asset and liability portfolio of the insurance company.

\section{Results}

We first discuss the results from the bank's perspective under the different calibrations. The focus is on the effects on the bank's probability of default and the fair credit spread of bonds. In a second step, we present our findings on the insurer's capital requirements for holding different bond types under the Solvency II standard model as well as the internal model.

Figure 2 reports the results for the baseline calibration (I). Subsequently, Figures 3 and 4 correspond to the calibrations II and III, in which we vary the bond's trigger value. Figure 5 illustrates the results for a lower conversion ratio. Each Figure (2-5) depicts the bank's 5-year probability of default and the resulting fair credit spreads in the upper left and right corner respectively, whereas the insurer's capital requirements resulting from the Solvency II standard model and the internal model are illustrated in the bottom left and right corner.

\subsection{Bank}

In this section, we investigate how the fair credit spread and the bank's probability of default derived from our model change with parameter inputs.

Figure 2.2 plots the fair credit spreads for the four considered bond types under the baseline calibration (I) for varying bank risk $\sigma_{V}$. The credit spreads increase with bank risk since the probability of high losses increases. In other words, a more volatile loan portfolio raises credit spreads (see Table 3). In comparison to the non-convertible bond, the spread on the CoCo (SAC) is significantly larger due to the possibility of conversion following a loss in the bank's asset (and equity) value. Since the conversion trigger is higher than the bankruptcy barrier, bankruptcy cannot precede conversion. Interestingly, the credit spread of a CoCo (HTM) is even higher. In contrast to a CoCo (SAC), bank shares will be held to maturity, thus, the investor participates in possible future bank losses. We observe the highest credit spread for the write-down bond since upon conversion, the investor does not recover the converted amount. For the bank, issuing a write-down bond leads to the highest refinancing cost and default probability among convertible debt.

If all of the benchmark parameters are maintained except one assumes little or no bank 
risk, then all credit spreads are zero. Thus, we find that the possibility of larger losses in the bank's asset value (high $\sigma_{V}$ ) has an important impact on the fair credit spread of contingent convertible debt. In line with the findings of Chen et al. (2013), our results show that replacing non-convertible debt with contingent convertible debt reduces the default probability (illustrated in Figure 2.1).

Calibration II increases the trigger value to $6.125 \%$ and thus increases the probability of conversion for investors. As a result, the credit spreads of write-down, CoCo (SAC) and CoCo (HTM) bonds increase. Particularly the difference between the spreads for CoCo and write-down bond increases since the probability of conversion is higher and thus the frequency of states in which the write-down bond holder realizes a loss (see Table 4). Moreover, the increased credit spreads lead to higher refinancing costs for the bank and thus the five-year default probabilities for CoCo and write-down bond issuing banks increase in comparison to the baseline calibration.

Calibration III reduces the trigger event to an equity capital ratio of $4.125 \%$. A lower trigger has the advantage of making conversion less likely. As a result, credit spreads decrease (Table 5). This, in turn, leads to smaller refinancing costs for the bank and thus also reduces its default probability.

Calibration IV assumes conversion below par with a conversion ratio of $\phi=0.25$. This corresponds to a write-down factor of $75 \%$. Since the change in the conversion ratio reduces the payout profiles of the CoCo (SAC) and the CoCo (HTM), our main observation is that the fair credit spreads increase towards the level of the write-down bond (Figure 5.2). In other words, CoCo investors anticipate that they will receive a lower value at conversion. This makes CoCos more expensive for the bank as a source of funding and in turn increases the bank's default probability compared to the baseline.

\subsection{Insurer}

In the following section, we present the insurer's capital requirements under the Solvency II standard model and the internal model. In addition, we study the sensitivity with respect to the CoCo design as well as the bank's risk appetite.

\subsubsection{Standard Model}

Figure 2.3 illustrates the resulting capital requirements for the insurer from the Solvency II standard model under the baseline calibration (I) for varying bank risk $\sigma_{V}$. We find that capital requirements for each bond type are similar for low $\sigma_{V}$ and increase step-wise with bank risk. 
Recall from Section 3.3.4 that the risk factor in the spread risk module is a step function that increases with the credit quality of the bond issuer. Thus, for low bank risk, all bonds share the same risk factor since the bank's default probability is the same (see Table 6).

Our results show that for moderate bank risk, the capital requirements for CoCo (SAC) and CoCo (HTM) are slightly higher than for the non-convertible bond and the write-down bond (Figure 2.3). This is due to the increasing amount of expected stock holdings stemming from the higher conversion risk that we assign to the equity risk module (see Equation (18)). For higher $\sigma_{V}$, the capital requirements for non-convertible bond holders increase faster than for all other bond types. This means that the increase in the risk factor $F^{u p}$ (rating) for non-convertible debt is steeper than for contingent convertible debt. In addition, the modified duration factor in the spread module (see Equation (22)) decreases faster for convertible debt than for non-convertible debt. As a result, the standard model assigns the lowest capital charges to the write-down bond, since no additional risk is transferred to the equity risk module and the write-down bond exhibits the smallest modified duration of all bonds.

For high bank risk $\left(\sigma_{V}=0.1\right)$, holding a CoCo (HTM) leads to the highest capital charges since in this case the largest amount of expected stock holdings is assigned to the equity risk module. For any $\sigma_{V}$, the standard model suggests insurers to invest particularly into writedown bonds to minimize capital requirements. However, since the standard model is not able to recognize the comparably high risk of the write-down bond, this suggestion is flawed.

As a result of the increased trigger in calibration II $(k=6.125 \%)$, capital requirements for the write-down bond, the CoCo (SAC) and the CoCo (HTM) increase. For the CoCo (HTM), the standard model assigns higher expected stock holdings to the equity risk module, thus additionally increasing the overall capital charge. As a result, the required capital for CoCos is larger than for the non-convertible bond (Figure 3.3).

Calibration III reduces the trigger event to an equity capital ratio of $4.125 \%$, which means a conversion becomes less likely. As a result, the standard model reduces capital requirements for convertible debt.

A change in the conversion ratio from $\phi=0.80$ to $\phi=0.25$ increases the fair credit spread on bonds since investors anticipate the resulting losses (calibration IV). However the standard model is not able to recognize this additional risk as the expected stock holdings decrease. As a result, for a lower conversion ratio, the standard model wrongfully lowers capital requirements for the CoCo (SAC) and the CoCo (HTM). 


\subsubsection{Internal Model}

Figure 2.4 depicts the capital requirements for the insurer at time $t=0$ from the internal model under the baseline calibration (I) for varying bank risk $\sigma_{V}$. As under the standard model, capital requirements for each bond type are similar for lower $\sigma_{V}$ (compare Table 6). With increasing bank risk, capital requirements for write-down bond holders increase first. This bond type contains the highest risk since in the event of conversion, (part of) the face value is bailedin. When further increasing the bank risk, also the capital requirements for the CoCo (SAC) and the CoCo (HTM) become larger (Table 7).

Note that the capital charge for the CoCo (SAC) is higher than for the CoCo (HTM) in the beginning. However this changes with increasing bank risk. The reason is that the CoCo (HTM) offers an opportunity for higher payouts, since bank shares are held to maturity. For low bank risk, this is clearly an advantage. However, it becomes disadvantageous for high $\sigma_{V}$ since the volatility of the bank shares increases the overall volatility of the insurer's asset portfolio thus raising the capital requirements. Note that this also applies for calibrations (II) and (III) for lower and higher bank risk respectively (see Tables 8 and 9).

Similar to the standard model, for moderate bank risk, convertible debt leads to higher capital requirements than non-convertible debt. The reason is that conversion occurs prior to default thus increasing the risk of the write-down bond (loss upon conversion), CoCo (SAC) (no further cash flows after conversion) and CoCo (HTM) (higher asset volatility after conversion).

For higher bank risk the situation changes. We observe a drastic increase in capital requirements for non-convertible debt holders up to the level of the write-down bond. For the CoCos, capital requirements increase at a smaller pace. Whereas the CoCo is able to replenish the bank's equity capital ratio and thereby indirectly reduces capital requirements for the insurer, the non-convertible bond depreciates in value due to the worsening of the bank's credit rating. This underlines the benefits from holding a CoCo bond.

Even though higher bank risk leads to an increasing frequency of conversion, the results from the internal model suggest that life insurers benefit from investing in contingent convertibles if the underlying bank risk is moderate. Due to the replacement of non-convertible debt with contingent convertible debt, the bank's default risk decreases, thus lowering the insurer's capital requirements for the bank investment. At the same time, the credit spread increases since a CoCo conversion precedes a non-convertible bond default.

As a result of an increased trigger in calibration II $(k=6.125 \%)$, capital requirements for the CoCo (SAC), CoCo (HTM) and the write-down bond increase (Figure 3.4) due to higher 
conversion risk. A higher trigger means that a conversion happens already for lower bank risk. In contrast, calibration III reduces the trigger event to an equity capital ratio of $4.125 \%$, thus a conversion becomes less likely. As a result, capital requirements for convertible debt decrease.

Calibration IV assumes conversion below par with a conversion ratio of $\phi=0.25$. We observe that the capital requirements increase faster since the payoff profile becomes more risky. For higher bank risk, the advantage of holding a CoCo thus shrinks.

To study the growth potential of CoCos, Tables 6 to 9 illustrate the insurer's capital charges for increasing 5 -year default probability of the bank. ${ }^{32}$ In the baseline calibration, we find that CoCos lead to the smallest capital requirements when the bank's credit rating is lower than $A A A$. This is also the case when varying the CoCo's trigger. From our results, we conclude that the highest growth potential from an insurer's point of view is a CoCo (HTM) bond with an investment grade lower than $A A A$. Furthermore, for banks rated $B B B$ or lower, an insurer benefits from buying a CoCo (SAC) instead of a CoCo (HTM) since the higher volatility of lower rated banks increases the insurer's capital requirements. Consequently, the higher the trigger, the more the insurer benefits from the CoCo (SAC) and vice versa.

A comparison between the capital requirements resulting from the Solvency II standard model and the internal model reveals significant differences. As Figures 2.3 and 2.4 illustrate, the standard model overestimates the capital charge in case of low bank risk. At the same time, capital requirements for high bank risk are underestimated (compare Table 6 and Table 7 ). This is due to the fact that the internal model recognizes the additional risk a convertible bond is exposed to, whereas the standard model treats a convertible bond as a non-convertible bond. While the internal model forecasts possible bank scenarios and takes into account resulting effects for the insurance balance sheet, the standard model uses a simple factor approach based on the credit quality of the bond issuer to estimate the spread risk.

Although the standard approach is easier to implement, the insurance company's risk situation is not sufficiently reflected by the predefined scenarios, both over- and underestimating the risk associated with the CoCo bond depending on the bank risk. In contrast, the internal model allows for adjustments and differentiated assumptions to better reflect the insurer's individual risk situation.

\footnotetext{
${ }^{32}$ The accompanying letter ratings represent the Standard \& Poor's rating scale.
} 


\section{Summary and Conclusion}

In the aftermath of the financial crisis, regulators propose contingent convertibles (CoCos) as a preferred financing instrument for banks to enhance financial stability and lessen the severity of future economic crises. However, such debt should be held outside the banking system. As the largest purchaser of bank bonds in Europe, especially life insurers could serve as potential CoCo bond holders. As a matter of fact, the growing number of banks issuing CoCo bonds leads to a rising awareness of these hybrid securities among life insurers as they are constantly looking for high-yield investments into bond-like asset classes.

To assess the effects of CoCos on banks' and insurers' risk situations, we develop a stylized model with a direct financial connection between banking and insurance. We evaluate the insurers' capital requirements under the proposed Solvency II standard model as well as under an internal model that ex-ante anticipates additional risks due to possible conversion of the CoCo bond into bank shares.

The numerical results reveal large differences in the capital charges for insurers under the standard model and the internal model. Since the current standardized assessment of market risk depends on relatively crude risk weights, it is not able to reflect the entire risk profile of a CoCo bond. In contrast, an internal model can recognize the full risk return profile through dynamic modeling techniques and therefore evaluates the actual risk situation of the company. By varying the CoCo bond's trigger value and the conversion ratio as well as the bank's risk appetite, we find that the standard model can mislead CoCo investors and does produce economically irrational incentives. For example, by increasing the trigger value, other things being equal, capital requirements under the Solvency II standard model wrongfully decrease while they increase under the internal model.

From the internal model, we learn that capital requirements for CoCo bonds increase with increasing trigger value, decreasing conversion ratio as well as increasing bank risk. In addition, CoCos lead to higher capital charges than non-convertible bonds if bank risk is low, and to lower capital requirements if bank risk is high. For low bank risk, an increase in capital requirements for CoCos is accompanied by an increase in the credit spread. For high bank risk, insurers clearly benefit from buying CoCos due to lower capital charges and a higher coupon rate. In this case, holding a CoCo clearly dominates holding a non-convertible bond. Therefore, insurers might even accept a reduction in the fair bond spread due to the reduction of risk capital.

As a potential growth area for CoCos from an insurer's point of view, we identify CoCo bonds from lower than $A A A$ rated counter-parties. 
The results of our analysis depend on both the calibration of the model and on the necessary simplifications adopted. The insurer's capital requirements depend on its simplified asset structure and indirectly on the stylized liability structure of the bank. A more complex debt structure (as implemented in Pennacchi (2011)) could lead to a different effect of CoCos on the bank and thus the insurer's capital charges. This could improve our analysis and add robustness to our results. In addition, the model relies on simplifying assumptions that considerably influence the final result. In general, the model is a reduced version of a bank and a life insurer's balance sheet without product line diversification, group diversification or reinsurance activities. Moreover, a stochastic interest rate development or policyholders' reactions are missing.

Furthermore, the analysis with respect to the upcoming Solvency II regulation implies the use of the Value-at-Risk measure. However, under other regulatory frameworks such as the Swiss Solvency Test, insurance companies have to quantify capital requirements using the Tail Value-at-Risk. A change in the risk measure can change our results and thus the regulatory incentives for insurance companies to buy CoCos.

Our results have profound economic implications. The analyses reveal that the current set-up and calibration of the Solvency II standard formula for market risk are inadequate with respect to the treatment of contingent convertible bonds. By highlighting substantial weaknesses of the market risk module, we hope that our results provide an additional impulse for improving it.

In future research, one could study the effects of changes in the fair bond spread and the insurer's capital requirements on the risk-adjusted return to insurance shareholders. While the fair bond spread is based on the default put option value of the bank, the capital requirements are based on the distribution of the insurer's equity capital and the regulatory risk measure. Such an analysis could result in the quantification of reservation spreads that insurance companies would demand in order to be sufficiently compensated for the changes in capital requirements under Solvency II or different regulatory frameworks. Another interesting area for further research is the behavior of both the bank and the investor at conversion. Clearly, the investor's decision to sell at conversion can contribute to a fire sale spiral which in turn reduces the stabilization effect of the CoCo bond. A comprehensive study about the optimal behavior would complement our analysis. 
Figures
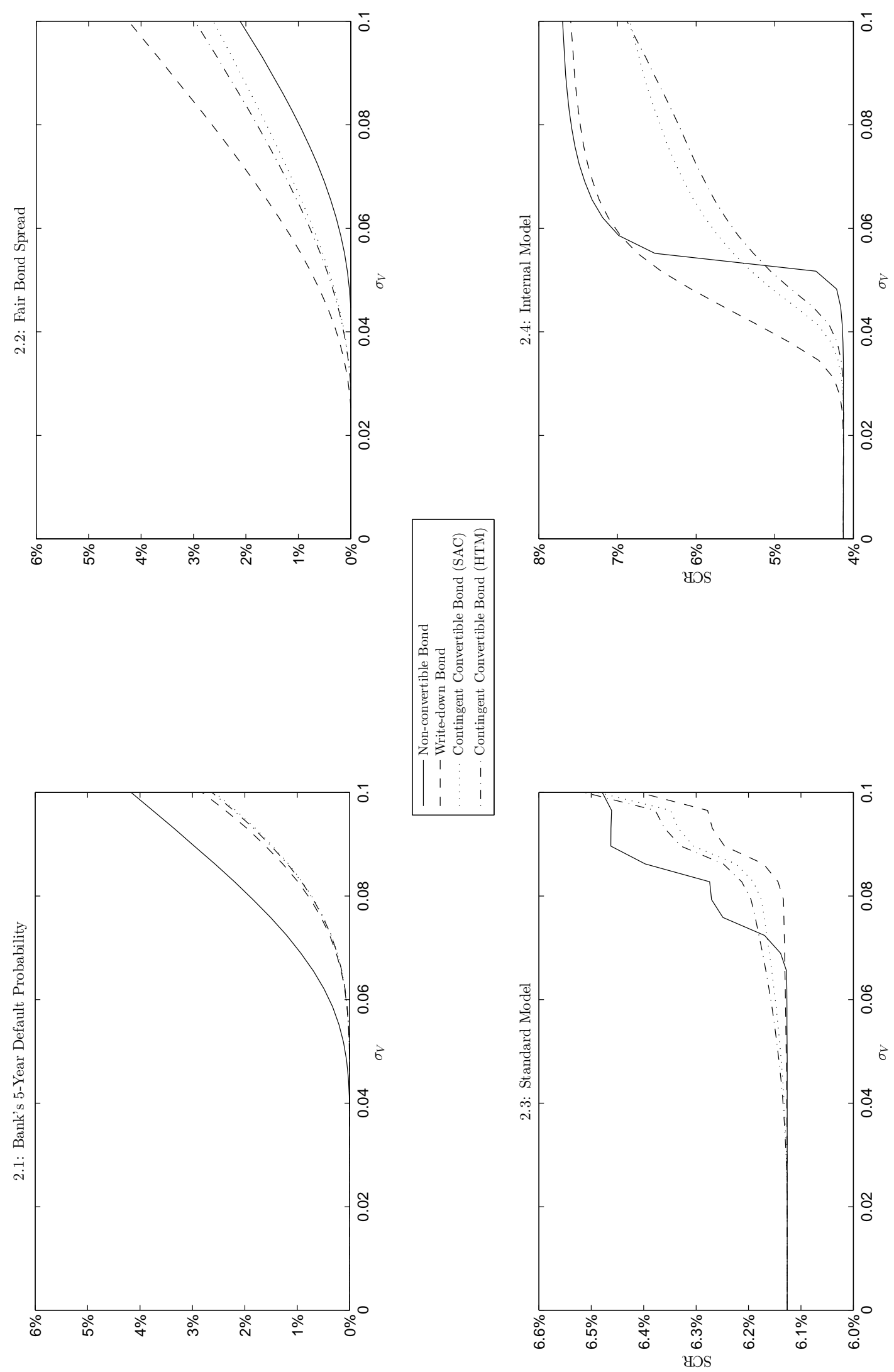

Figure 2: Results from calibration I with $k=5.125 \%, E_{0}^{B} / V_{0}=12.5 \%$ and $\phi=0.80$. 

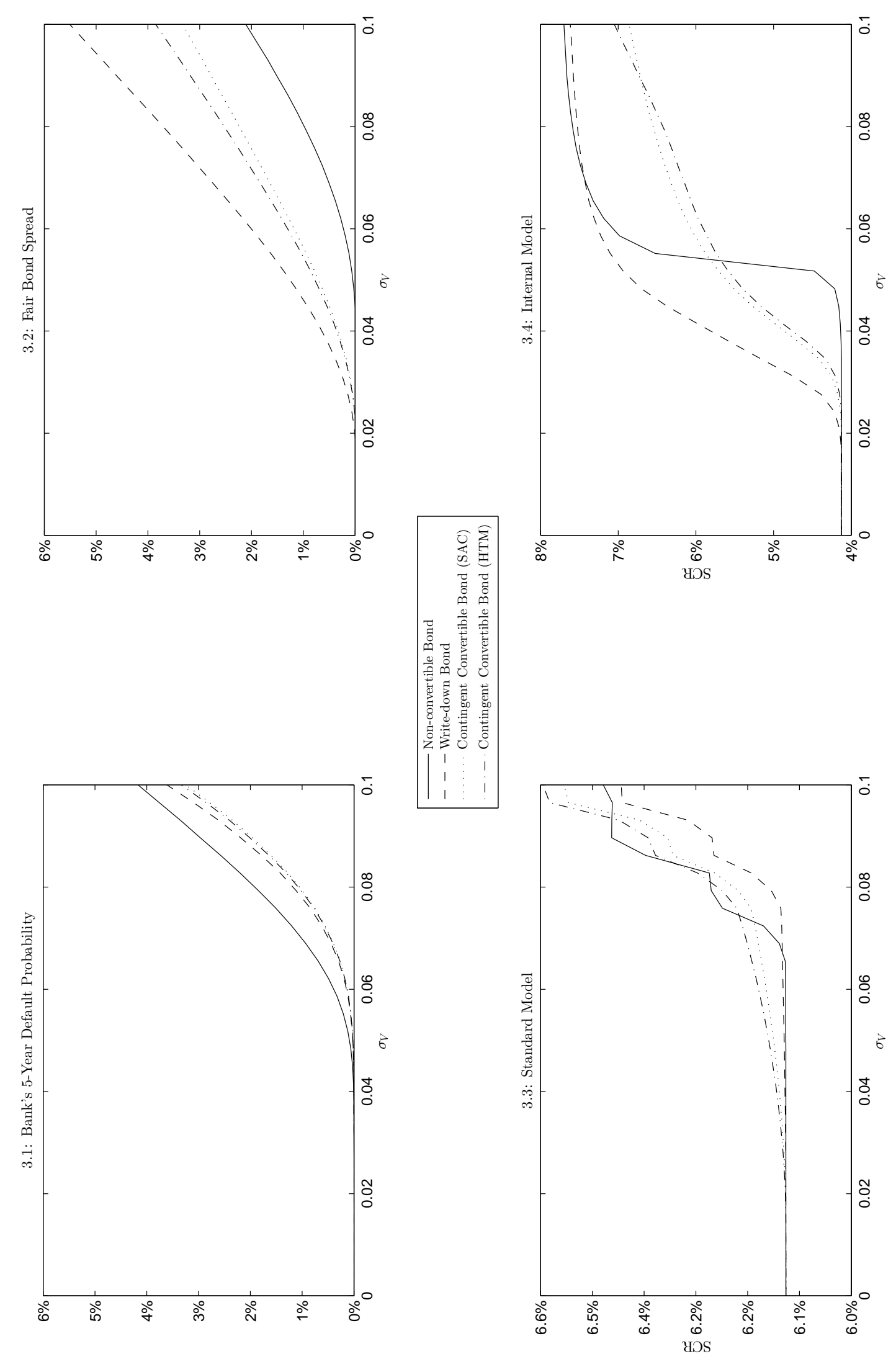

Figure 3: Results from calibration II with $k=6.125 \%, E_{0}^{B} / V_{0}=12.5 \%$ and $\phi=0.80$. 

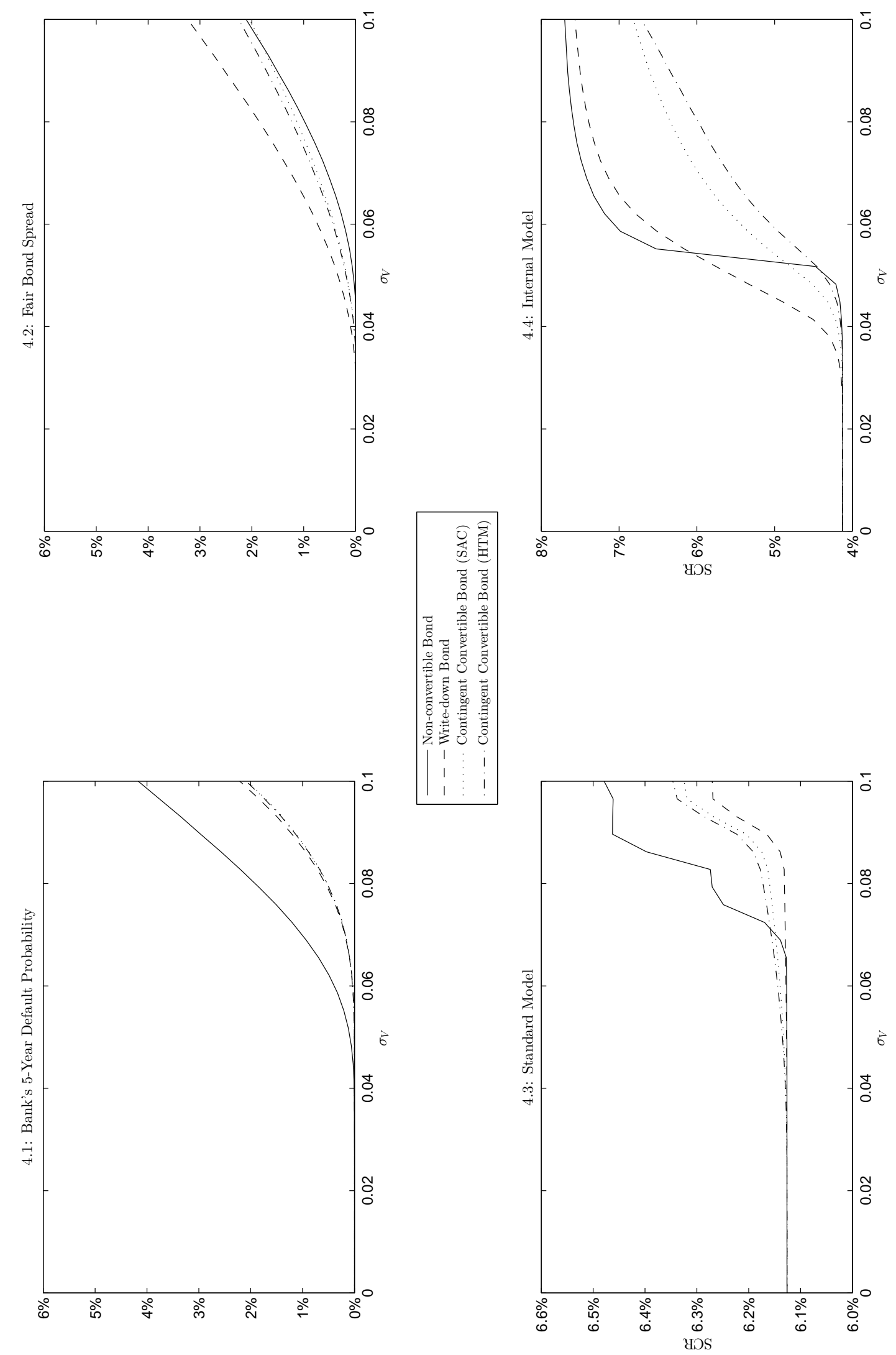

Figure 4: Results from calibration III with $k=4.125 \%, E_{0}^{B} / V_{0}=12.5 \%$ and $\phi=0.80$. 

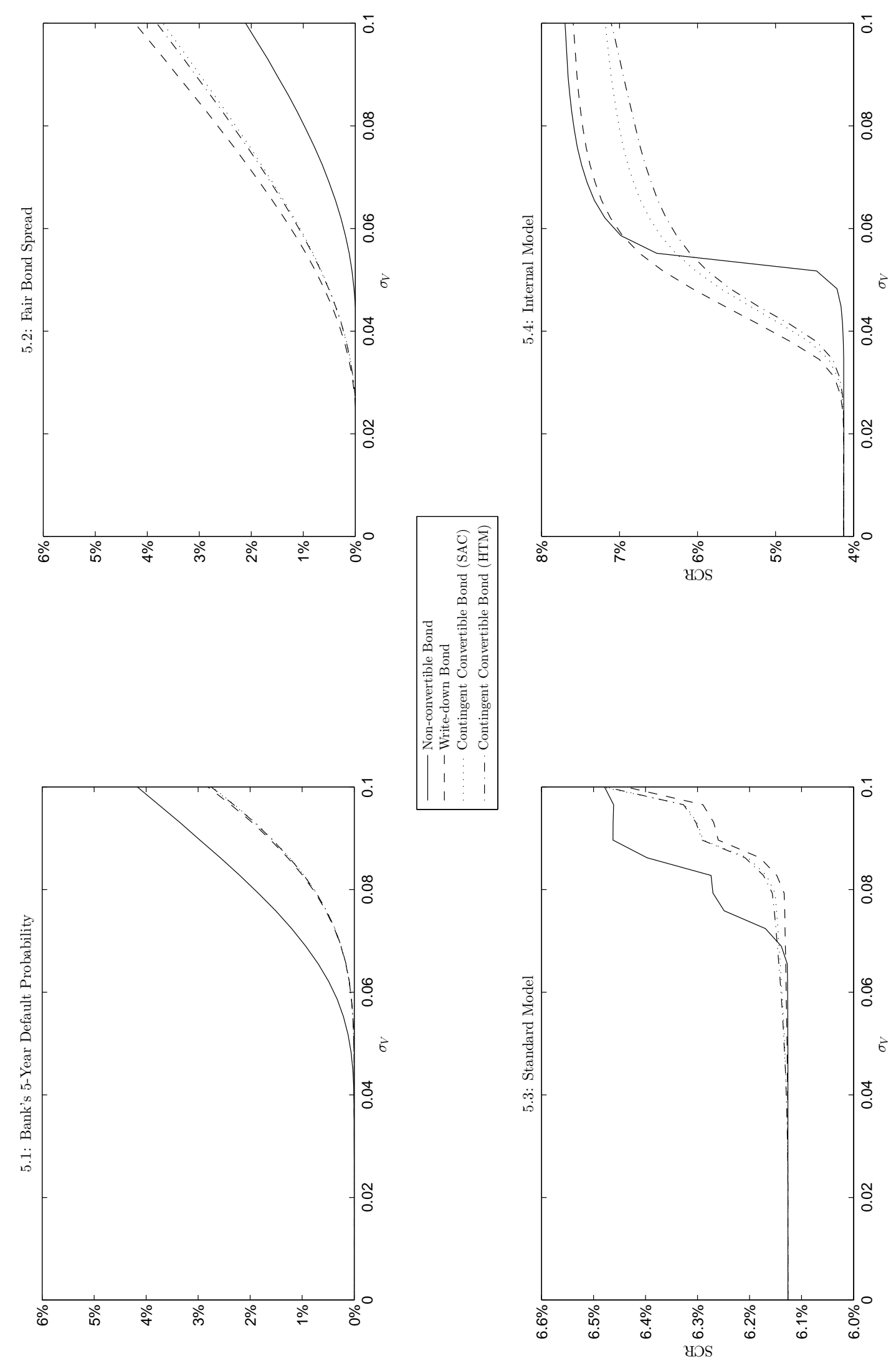

Figure 5: Results from calibration IV with $k=5.125 \%, E_{0}^{B} / V_{0}=12.5 \%$ and $\phi=0.25$. 


\section{Tables}

\begin{tabular}{cc|cccc}
\hline \hline \multirow{2}{*}{ 5Y PD } & \multirow{2}{*}{ Rating } & \multicolumn{4}{|c}{ Fair Spread } \\
& NoCo & CoCo(SAC) & CoCo(HTM) & WriteDown \\
\hline $0.0 \%$ & $A A A$ & $0.00 \%$ & $0.00 \%$ & $0.00 \%$ & $0.00 \%$ \\
$0.1 \%$ & $A A A$ & $0.07 \%$ & $0.94 \%$ & $1.03 \%$ & $1.60 \%$ \\
$0.2 \%$ & $A A$ & $0.12 \%$ & $1.09 \%$ & $1.20 \%$ & $1.84 \%$ \\
$0.3 \%$ & $A A$ & $0.19 \%$ & $1.25 \%$ & $1.38 \%$ & $2.08 \%$ \\
$0.4 \%$ & $A A$ & $0.28 \%$ & $1.41 \%$ & $1.56 \%$ & $2.33 \%$ \\
$0.5 \%$ & $A$ & $0.38 \%$ & $1.57 \%$ & $1.75 \%$ & $2.59 \%$ \\
$1.0 \%$ & $A$ & $0.50 \%$ & $1.92 \%$ & $2.14 \%$ & $2.86 \%$ \\
$1.5 \%$ & $A$ & $0.79 \%$ & $2.09 \%$ & $2.35 \%$ & $3.41 \%$ \\
$2.0 \%$ & $B B B$ & $1.12 \%$ & $2.44 \%$ & $2.76 \%$ & $3.68 \%$ \\
$2.5 \%$ & $B B B$ & $1.30 \%$ & $2.62 \%$ & $2.97 \%$ & $3.96 \%$ \\
$3.0 \%$ & $B B B$ & $1.49 \%$ & $2.80 \%$ & $3.18 \%$ & $4.24 \%$ \\
\hline \hline
\end{tabular}

Table 3: Fair spread for different bond types (calibration I).

\begin{tabular}{cc|cccc}
\hline \hline \multirow{2}{*}{ 5Y PD } & \multirow{2}{*}{ Rating } & NoCo & CoCo(SAC) & CoCo(HTM) & WriteDown \\
\hline $0.0 \%$ & $A A A$ & $0.00 \%$ & $0.00 \%$ & $0.00 \%$ & $0.00 \%$ \\
$0.1 \%$ & $A A A$ & $0.07 \%$ & $1.11 \%$ & $1.22 \%$ & $1.89 \%$ \\
$0.2 \%$ & $A A$ & $0.12 \%$ & $1.28 \%$ & $1.42 \%$ & $2.17 \%$ \\
$0.3 \%$ & $A A$ & $0.19 \%$ & $1.46 \%$ & $1.62 \%$ & $2.46 \%$ \\
$0.4 \%$ & $A A$ & $0.28 \%$ & $1.64 \%$ & $1.83 \%$ & $2.75 \%$ \\
$0.5 \%$ & $A$ & $0.38 \%$ & $1.83 \%$ & $2.05 \%$ & $3.04 \%$ \\
$1.0 \%$ & $A$ & $0.50 \%$ & $2.38 \%$ & $2.48 \%$ & $3.65 \%$ \\
$1.5 \%$ & $A$ & $0.79 \%$ & $2.57 \%$ & $2.93 \%$ & $3.95 \%$ \\
$2.0 \%$ & $B B B$ & $1.12 \%$ & $2.75 \%$ & $3.16 \%$ & $4.58 \%$ \\
$2.5 \%$ & $B B B$ & $1.30 \%$ & $2.95 \%$ & $3.38 \%$ & $4.88 \%$ \\
$3.0 \%$ & $B B B$ & $1.49 \%$ & $3.14 \%$ & $3.62 \%$ & $5.20 \%$ \\
\hline \hline
\end{tabular}

Table 4: Fair spread for different bond types (calibration II).

\begin{tabular}{cc|cccc}
\hline \hline \multirow{2}{*}{ 5Y PD } & \multirow{2}{*}{ Rating } & NoCo & CoCo(SAC) & CoCo(HTM) & WriteDown \\
\hline $0.0 \%$ & $A A A$ & $0.00 \%$ & $0.00 \%$ & $0.00 \%$ & $0.00 \%$ \\
$0.1 \%$ & $A A A$ & $0.07 \%$ & $0.58 \%$ & $0.63 \%$ & $1.00 \%$ \\
$0.2 \%$ & $A A$ & $0.12 \%$ & $0.70 \%$ & $0.76 \%$ & $1.19 \%$ \\
$0.3 \%$ & $A A$ & $0.19 \%$ & $0.83 \%$ & $0.89 \%$ & $1.39 \%$ \\
$0.4 \%$ & $A A$ & $0.28 \%$ & $0.96 \%$ & $1.04 \%$ & $1.59 \%$ \\
$0.5 \%$ & $A$ & $0.38 \%$ & $1.10 \%$ & $1.20 \%$ & $1.81 \%$ \\
$1.0 \%$ & $A$ & $0.50 \%$ & $1.56 \%$ & $1.71 \%$ & $2.27 \%$ \\
$1.5 \%$ & $A$ & $0.79 \%$ & $1.88 \%$ & $1.88 \%$ & $2.74 \%$ \\
$2.0 \%$ & $B B B$ & $1.12 \%$ & $2.04 \%$ & $2.25 \%$ & $2.99 \%$ \\
$2.5 \%$ & $B B B$ & $1.30 \%$ & $2.21 \%$ & $2.63 \%$ & $3.24 \%$ \\
$3.0 \%$ & $B B B$ & $1.49 \%$ & $2.37 \%$ & $3.00 \%$ & $3.48 \%$ \\
\hline \hline
\end{tabular}

Table 5: Fair spread for different bond types (calibration III). 


\begin{tabular}{cc|cccc}
\hline \hline 5Y PD & \multirow{2}{*}{ Rating } & NoCo & CoCo(SAC) & $\begin{array}{c}\text { SCR } \\
\text { CoCo(HTM) }\end{array}$ & WriteDown \\
\hline $0.0 \%$ & $A A A$ & $6.13 \%$ & $6.13 \%$ & $6.13 \%$ & $6.13 \%$ \\
$0.1 \%$ & $A A A$ & $6.13 \%$ & $6.16 \%$ & $6.17 \%$ & $6.13 \%$ \\
$0.2 \%$ & $A A$ & $6.13 \%$ & $6.16 \%$ & $6.17 \%$ & $6.13 \%$ \\
$0.3 \%$ & $A A$ & $6.13 \%$ & $6.17 \%$ & $6.18 \%$ & $6.13 \%$ \\
\hline $0.4 \%$ & $A A$ & $6.13 \%$ & $6.17 \%$ & $6.19 \%$ & $6.13 \%$ \\
$0.5 \%$ & $A$ & $6.14 \%$ & $6.18 \%$ & $6.20 \%$ & $6.13 \%$ \\
$1.0 \%$ & $A$ & $6.14 \%$ & $6.22 \%$ & $6.25 \%$ & $6.14 \%$ \\
$1.5 \%$ & $A$ & $6.25 \%$ & $6.30 \%$ & $6.33 \%$ & $6.25 \%$ \\
$2.0 \%$ & $B B B$ & $6.27 \%$ & $6.33 \%$ & $6.36 \%$ & $6.27 \%$ \\
$2.5 \%$ & $B B B$ & $6.40 \%$ & $6.35 \%$ & $6.38 \%$ & $6.28 \%$ \\
$3.0 \%$ & $B B B$ & $6.46 \%$ & $6.49 \%$ & $6.51 \%$ & $6.41 \%$ \\
\hline \hline
\end{tabular}

Table 6: Insurer's SCR from the standard model in \% of total assets with different bond types and default probabilities (calibration I).

\begin{tabular}{cc|cccc}
\hline \hline \multirow{2}{*}{ 5Y PD } & Rating & NoCo & CoCo(SAC) & $\begin{array}{l}\text { SCR } \\
\text { CoCo(HTM) }\end{array}$ & WriteDown \\
\hline $0.0 \%$ & $A A A$ & $4.13 \%$ & $4.13 \%$ & $4.13 \%$ & $4.13 \%$ \\
$0.1 \%$ & $A A A$ & $4.47 \%$ & $6.03 \%$ & $5.77 \%$ & $7.12 \%$ \\
\hline $0.2 \%$ & $A A$ & $6.52 \%$ & $6.15 \%$ & $5.89 \%$ & $7.23 \%$ \\
$0.3 \%$ & $A A$ & $6.98 \%$ & $6.26 \%$ & $6.00 \%$ & $7.31 \%$ \\
$0.4 \%$ & $A A$ & $7.19 \%$ & $6.36 \%$ & $6.10 \%$ & $7.38 \%$ \\
$0.5 \%$ & $A$ & $7.32 \%$ & $6.44 \%$ & $6.20 \%$ & $7.43 \%$ \\
$1.0 \%$ & $A$ & $7.42 \%$ & $6.60 \%$ & $6.31 \%$ & $7.52 \%$ \\
$1.5 \%$ & $A$ & $7.54 \%$ & $6.67 \%$ & $6.53 \%$ & $7.55 \%$ \\
$2.0 \%$ & $B B B$ & $7.61 \%$ & $6.73 \%$ & $6.64 \%$ & $7.56 \%$ \\
\hline $2.5 \%$ & $B B B$ & $7.64 \%$ & $6.79 \%$ & $6.80 \%$ & $7.58 \%$ \\
$3.0 \%$ & $B B B$ & $7.66 \%$ & $6.84 \%$ & $6.88 \%$ & $7.59 \%$ \\
\hline \hline
\end{tabular}

Table 7: Insurer's SCR from the internal model in \% of total assets with different bond types and default probabilities (calibration I).

\begin{tabular}{cc|cccc}
\hline \hline \multirow{2}{*}{ 5Y PD } & \multirow{2}{*}{ Rating } & NoCo & CoCo(SAC) & $\begin{array}{l}\text { SCR } \\
\text { CoCo(HTM) }\end{array}$ & WriteDown \\
\hline $0.0 \%$ & $A A A$ & $4.13 \%$ & $4.13 \%$ & $4.13 \%$ & $4.13 \%$ \\
$0.1 \%$ & $A A A$ & $4.47 \%$ & $6.01 \%$ & $5.86 \%$ & $7.22 \%$ \\
\hline $0.2 \%$ & $A A$ & $6.52 \%$ & $6.13 \%$ & $5.97 \%$ & $7.31 \%$ \\
$0.3 \%$ & $A A$ & $6.98 \%$ & $6.23 \%$ & $6.06 \%$ & $7.38 \%$ \\
$0.4 \%$ & $A A$ & $7.19 \%$ & $6.32 \%$ & $6.15 \%$ & $7.42 \%$ \\
$0.5 \%$ & $A$ & $7.32 \%$ & $6.40 \%$ & $6.23 \%$ & $7.47 \%$ \\
$1.0 \%$ & $A$ & $7.49 \%$ & $6.60 \%$ & $6.40 \%$ & $7.52 \%$ \\
$1.5 \%$ & $A$ & $7.54 \%$ & $6.66 \%$ & $6.61 \%$ & $7.54 \%$ \\
\hline $2.0 \%$ & $B B B$ & $7.61 \%$ & $6.71 \%$ & $6.72 \%$ & $7.58 \%$ \\
$2.5 \%$ & $B B B$ & $7.64 \%$ & $6.76 \%$ & $6.83 \%$ & $7.59 \%$ \\
$3.0 \%$ & $B B B$ & $7.66 \%$ & $6.81 \%$ & $6.94 \%$ & $7.60 \%$ \\
\hline \hline
\end{tabular}

Table 8: Insurer's $S C R$ from the internal model in \% of total assets with different bond types and default probabilities (calibration II). 


\begin{tabular}{cc|cccc}
\hline \hline \multirow{2}{*}{ 5Y PD } & \multirow{2}{*}{ Rating } & NoCo & CoCo(SAC) & $\begin{array}{c}\text { SCR } \\
\text { CoCo(HTM) }\end{array}$ & WriteDown \\
\hline $0.0 \%$ & $A A A$ & $4.13 \%$ & $4.13 \%$ & $4.13 \%$ & $4.13 \%$ \\
$0.1 \%$ & $A A A$ & $4.47 \%$ & $5.77 \%$ & $5.38 \%$ & $6.99 \%$ \\
\hline $0.2 \%$ & $A A$ & $6.52 \%$ & $6.08 \%$ & $5.54 \%$ & $7.13 \%$ \\
$0.3 \%$ & $A A$ & $6.98 \%$ & $6.21 \%$ & $5.69 \%$ & $7.24 \%$ \\
$0.4 \%$ & $A A$ & $7.19 \%$ & $6.32 \%$ & $5.83 \%$ & $7.32 \%$ \\
$0.5 \%$ & $A$ & $7.32 \%$ & $6.42 \%$ & $5.96 \%$ & $7.38 \%$ \\
$1.0 \%$ & $A$ & $7.49 \%$ & $6.60 \%$ & $6.34 \%$ & $7.50 \%$ \\
$1.5 \%$ & $A$ & $7.54 \%$ & $6.68 \%$ & $6.46 \%$ & $7.52 \%$ \\
$2.0 \%$ & $B B B$ & $7.61 \%$ & $6.75 \%$ & $6.58 \%$ & $7.55 \%$ \\
$2.5 \%$ & $B B B$ & $7.64 \%$ & $6.81 \%$ & $6.71 \%$ & $7.57 \%$ \\
$3.0 \%$ & $B B B$ & $7.66 \%$ & $6.88 \%$ & $6.85 \%$ & $7.59 \%$ \\
\hline \hline
\end{tabular}

Table 9: Insurer's $S C R$ from the internal model in \% of total assets with different bond types and default probabilities (calibration III). 


\section{Proofs}

We proof formula (9) with induction in $\delta_{T}$ :

Let $\delta_{T}=2$. Note that by convention, empty products are equal to 1 , that is $\prod_{i=j}^{n} f(i)=1$ for all $n<j$ and all functions $f$. With formula (8) follows

$$
\begin{aligned}
\Delta_{\delta_{T}}= & \sum_{j=1}^{2} \frac{\phi\left(k \cdot V_{T^{(j)}}-\left(E_{T^{(j)}}^{B}\right)^{+}\right)}{k \cdot V_{T^{(j)}}} \prod_{i=j+1}^{2} \frac{E_{T^{(i)}}^{B}}{k \cdot V_{T^{(i)}}} \\
= & \frac{\phi\left(k \cdot V_{T^{(1)}}-\left(E_{T^{(1)}}^{B}\right)^{+}\right)}{k \cdot V_{T^{(1)}}} \prod_{i=2}^{2} \frac{E_{T^{(i)}}^{B}}{k \cdot V_{T^{(i)}}}+\frac{\phi\left(k \cdot V_{T^{(2)}}-\left(E_{T^{(2)}}^{B}\right)\right.}{k \cdot V_{T^{(2)}}} \prod_{i=3}^{2} \frac{E_{T^{(i)}}^{B}}{k \cdot V_{T^{(i)}}} \\
= & \frac{\phi\left(k \cdot V_{T^{(1)}}-\left(E_{T^{(1)}}^{B}\right)^{+}\right)}{k \cdot V_{T^{(1)}}} \frac{E_{T^{(2)}}^{B}}{k \cdot V_{T^{(2)}}}+\frac{\phi\left(k \cdot V_{T^{(2)}}-\left(E_{T^{(2)}}^{B}\right)^{+}\right)}{k \cdot V_{T^{(2)}}} \\
= & \frac{E_{T^{(2)}}^{B} \frac{\phi\left(k \cdot V_{T^{(1)}}-\left(E_{T^{(1)}}^{B}\right)^{+}\right)}{k \cdot V_{T^{(1)}}}+\phi\left(k \cdot V_{T^{(2)}}-\left(E_{T^{(2)}}^{B}\right)^{+}\right)}{k \cdot V_{T^{(2)}}^{(8)}} \Delta_{2} .
\end{aligned}
$$

Let $\delta_{T} \rightarrow \delta_{T}+1$. By using the case $\delta_{T}=2$ and formula (8) it follows that the fraction of equity held after the $\left(\delta_{T}+1\right)$-th conversion is

$$
\begin{aligned}
& \frac{E_{T^{\left(\delta_{T}+1\right)}}^{B} \Delta_{\delta_{T}}+\phi\left(k \cdot V_{T^{(\delta+1)}}-\left(E_{T^{(\delta+1)}}^{B}\right)^{+}\right)}{k \cdot V_{T^{(\delta+1)}}} \\
= & \frac{E_{T^{\left(\delta_{T}+1\right)}}^{B}}{k \cdot V_{T^{(\delta+1)}}^{\delta_{T}}} \sum_{j=1}^{\phi} \frac{\phi\left(k \cdot V_{T^{(j)}}-\left(E_{T^{(j)}}^{B}\right)^{+}\right)}{k \cdot V_{T^{(j)}}} \prod_{i=j+1}^{\delta_{T}} \frac{E_{T^{(i)}}^{B}}{k \cdot V_{T^{(i)}}}+\frac{\phi\left(k \cdot V_{T^{(\delta+1)}}-\left(E_{T^{(\delta+1)}}^{B}\right)^{+}\right)}{\left.k \cdot V_{T^{\left(\delta_{T}+1\right)}}\right)} \\
= & \sum_{j=1}^{\delta_{T}+1} \frac{\phi\left(k \cdot V_{T^{(j)}}-\left(E_{T^{(j)}}^{B}\right)^{+}\right)}{k \cdot V_{T^{(j)}}} \prod_{i=j+1}^{\delta_{T}+1} \frac{E_{T^{(i)}}^{B}}{k \cdot V_{T^{(i)}}}=\Delta_{\delta_{T}+1} \cdot
\end{aligned}
$$




\section{References}

Avdjiev, S., Kartasheva, A. V., and Bogdanova, B. (2013). CoCos: A Primer. BIS Quarterly Review.

Bank for International Settlements (2011). Basel III: A global regulatory framework for more resilient banks and banking systems.

Brigo, D., Garcia, J., and Pede, N. (2013). CoCo Bonds Valuation with Equity and CreditCalibrated First Passage Structural Models. Working Paper.

Chen, N., Glasserman, P., Nouri, B., and Pelger, M. (2013). Contingent Capital, Tail Risk, and Debt-Induced Collapse. Columbia Business School Research Paper, (13-90).

Corcuera, J. M., Spiegeleer, J., Ferreiro-Castilla, A., Kyprianou, A., Madan, D., and Schoutens, W. (2013). Pricing of contingent convertibles under smile conform models. Journal of Credit Risk, 9(3):121-140.

Eling, M., Schmeiser, H., and Schmit, J. T. (2007). The Solvency II Process: Overview and Critical Analysis. Risk Management and Insurance Review, 10(1):69-85.

European Insurance and Occupational Pensions Authority (EIOPA) (2013a). EU/EEA (Re)Insurance Statistics (formerly Statistical Annex to EIOPA Financial Stability Report). www. eiopa. europa.eu/publications/financial-stability.

European Insurance and Occupational Pensions Authority (EIOPA) (2013b). Technical Specification on the Long Term Guarantee Assessment (Part I). https://eiopa. europa.eu/en/consultations/qis/insurance/long-term-guarantees-assessment/ technical-specifications/index.html.

European Insurance and Occupational Pensions Authority (EIOPA) (2013c). Technical Specification on the Long Term Guarantee Assessment (Part II). https://eiopa. europa.eu/en/consultations/qis/insurance/long-term-guarantees-assessment/ technical-specifications/index.html.

Federal Financial Supervisory Authority (BaFin) (2012). Mitteilungen der Bundesanstalt für Finandienstleistungsaufsicht. BaFin Journal.

Fitch Ratings (2011). Solvency II Set to Reshape Asset Allocation and Capital Markets. Insurance Rating Group Special Report. 
Flannery, M. (2005). No Pain, No Gain? Effecting Market Discipline via Reverse Convertible Debentures. In Scott, H., editor, Capital Adequacy Beyond Basel: Banking, Securities, and Insurance, pages 171-196. Oxford University Press, Oxford.

Gatzert, N. and Wesker, H. (2012). A Comparative Assessment of Basel II/III and Solvency II. The Geneva Papers on Risk and Insurance - Issues and Practice, 37(3):539-570.

Gesamtverband der Deutschen Versicherungswirtschaft e. V. (GDV) (2014). Statistical Yearbook of German Insurance 2014.

Glasserman, P. and Nouri, B. (2012). Contingent Capital with a Capital-Ratio Trigger. Management Science, 58(10):1816-1833.

Insurance Europe, Oliver Wyman (2013). Funding the Future: Insurers' role as institutional investors.

Krahnen, J. P. (2013). Rescue by Regulation? Key Points of the Liikanen Report. SAFE Policy Center White Paper Series, (9).

Laas, D. and Siegel, C. F. (2013). Basel Accords versus Solvency II: Regulatory Adequacy and Consistency Under the Postcrisis Capital Standards. Working Paper Series on Risk Management and Insurance, (132). University of St. Gallen.

Liikanen et al. (2012). High-level Expert Group on reforming the structure of the EU banking sector (Liikanen Report).

Pennacchi, G. (2011). A structural model of contingent bank capital. Working Paper, (10-04). Federal Reserve Bank of Cleveland.

Reichling, P., Bietke, D., and Henne, A. (2007). Praxishandbuch Risikomanagement und Rating: Ein Leitfaden. Betriebswirtschaftlicher Verlag Dr. Th. Gabler, 2. edition.

Shang, K. (2013). Understanding Contingent Capital. Technical report, Casualty Actuarial Society.

Swiss Financial Market Supervisory Authority (FINMA) (2011). Addressing Too Big To Fail The Swiss SIFI Policy.

Zähres, M. (2011). Contigent Convertibles - Bank Bonds take on a new look. Financial Market Special 79, Deutsche Bank Research. 


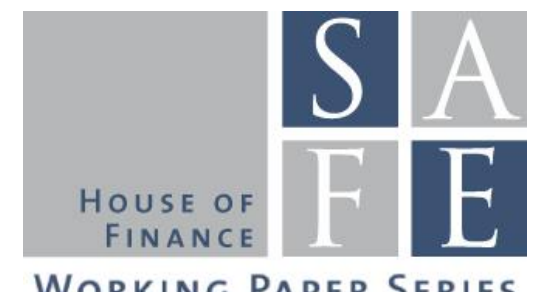

WORKING PAPER SERIES

\section{Recent Issues}

No. $97 \quad$ Tobias Niedrig

No.96 Jens-Hinrich Binder

No. 95 Loriana Pelizzon, Marti G.

Subrahmanyam, Davide Tomio, Jun Uno

No. 94 Claudia Lambert, Felix Noth, Ulrich Schüwer

No. 93 Shafik Hebous, Tom Zimmermann

No. 92 Christoph Hambel, Holger Kraft, Eduardo S. Schwartz

No.91 Anne-Caroline Hüser

No.90 Pinar Topal

No. 89 Julia Braun, Alfons J. Weichenrieder

No. 88 Ester Faia, Beatrice Weder di Mauro

No. 87 Iñaki Aldasoro, Domenico Delli Gatti, Ester Faia

No. 86 Agar Brugiavini, Danilo Cavapozzi, Mario Padula, Yuri Pettinicchi

No. 85 Holger Kraft, Claus Munk, Sebastian Wagner

No. 84 Raimond Maurer, Olivia S. Mitchell, Ralph Rogalla, Tatjana Schimetschek
Optimal Asset Allocation for interconnected

Life Insurers in the Low Interest Rate

Environment under Solvency Regulation

Banking Union and the Governance of Credit Institutions - A Legal Perspective

Sovereign Credit Risk, Liquidity, and ECB Intervention: Deus Ex Machina?

How Do Banks React to Catastrophic Events? Evidence from Hurricane Katrina

Revisiting the Narrative Approach of Estimating Tax Multipliers

Optimal Carbon Abatement in a Stochastic Equilibrium Model with Climate Change

Too Interconnected to Fail: A Survey of the Interbank Networks Literature

Fiscal Stimulus and Labor Market Flexibility

Does Exchange of Information between Tax Authorities Influence Multinationals' Use of Tax Havens?

Cross-Border Resolution of Global Banks

Bank Networks: Contagion, Systemic Risk and Prudential Policy

Financial education, literacy and investment attitudes

Housing Habits and Their Implications for LifeCycle Consumption and Investment

Will They Take the Money and Work? An Empirical Analysis of People's Willingness to Delay Claiming Social Security Benefits for a Lump Sum 